\title{
SABINA JELENC KRAŠOVEC - LIK ANDRAGOGINJE
}

Sodeč po tem, kar so o Sabini v svojih sožalnih sporočilih napisali tisti, ki so jo poznali, med njimi še posebno kolegice in kolegi ter sodelavke in sodelavci ter drugi strokovnjaki s področja izobraževanja odraslih, tako iz Slovenije kot tudi iz tujine, je bila žal prezgodaj umrla Sabina Jelenc Krašovec zgled uspešne andragoginje. To lahko razberemo iz sporočil, kot so: » v mojih mislih bo vedno ostala velika andragoginja in kolegica«; »koliko znanja, energije je odšlo, kljub kratkemu življenju je med mnoge ljudi zasejala znanje, prepričanja in voljo do izobraževanja odraslih«; »bila je predana stroki, kritična, neravnodušna do tega, kar se dogaja, in zelo angažirana«; »I found her to be a serious and enthusiastic colleague, who also enjoyed life to the full; Sabina was a favourite for many of us, she will not be forgotten by those who came to know her well«. Ob teh izbranih strokovnih opredelitvah pa tudi ne manjka sporočil, ki govorijo o njenih osebnostnih značilnostih ter načinu življenja in delovanja: »v mislih jo imam nasmejano, energično in vedno pripravljeno na iskriv pogovor «; »kar ne morem verjeti, da ni več tako energije polne Sabine, kakor smo jo poznali«; »koliko znanja, energije, dobrote je odšlo«; »zmeraj je znala stvari narediti zemeljske, postaviti življenje v ospredje«; »vsakič me je preplavila njena silovita energija, žar, ki se je širil kot blisk«; »bila je iskrena, pozitivna, polna energije in entuziazma, hkrati pa zelo pravična«; »bila je dragoceno sonce naše širše družine, akademskega in ostalega sveta, zato nikoli ne bo prenehala sijati«.

Ali to pomeni, da si je Sabina izbrala pravi poklic? Je na to kazalo, ko se je po osnovni šoli vpisala na gimnazijo pedagoške smeri? Ni nujno. Tedaj so se srednje šole ravnale po zahtevah usmerjenega izobraževanja in so si kandidati morali izbrati smer, ki je vodila $\mathrm{k}$ določenim poklicnim področjem in usmeritvam, kot so, če naštejem nekatere, naravoslovno in tehnično, jezikovno, pedagoško, zdravstveno ... . Poleg zgodnje usmeritve v poklic in kasneje $\mathrm{v}$ delo na izbranem področju je bil poglavitni namen takega usmerjanja odvračanje od splošnega izobraževanja, ker so odločevalci na področju vzgoje in izobraževanja ter oblikovalci družbenega razvoja in politike presodili, da se preveč učencev odloča za splošno izobraževalne smeri ter še posebej za družboslovna in humanistična področja namesto za tehniko in naravoslovje. Tako naj bi odpravljali neravnovesje med področji dela in poklici v praksi, saj naj bi šole tisti čas in na splošno dajale preveč družboslovcev ter premalo naravoslovcev in tehnikov, ki jih v družbi potem primanjkuje.

Sabina se je pred odločitvijo za študij želela prepričati o tem, za kakšen poklic naj bi bila najbolj primerna. Za tehnične poklice, medicino, študij s pomembnim deležem matematike in druga poklicna področja (izjema bi lahko bila veterina, a predvsem zato, ker je kot otrok imela rada živali) Sabina ni kazala zanimanja. Še najbližja ji je bila psihologija. 
Oglasila se je pri svetovalcu za visokošolske poklice, psihologu Zdenku Lapajnetu na Centru za razvoj univerze, da bi preverila ustreznost svoje poklicne namere. Svetovalec je na podlagi ugotovitev iz svetovalne obravnave njeno namero podprl in ji potrdil, da bi bila njena odločitev prava in bi bila psihologija pravi poklic zanjo. Število kandidatov, ki bi jih tisto leto sprejeli na študij psihologije, so določili tako, da so morali opraviti sprejemni preizkus, kot merilo za sprejem pa je poleg dovolj dobrega šolskega uspeha štelo število doseženih točk v vprašalniku, ki so ga morali izpolniti. V njem so bile različne zahteve, med drugim tudi uspešno rešene matematične naloge. Sabini so na koncu za sprejem na študij psihologije zmanjkale tri točke in na študij psihologije ni bila sprejeta. Sam sem bil do takega načina selekcije kandidatov zelo kritičen; menil sem, da bi psihologi morali biti sposobni presojati primernost kandidatov za delo psihologa s svojimi, psihološkimi sredstvi (zlasti s pogovorom in opazovanjem), ne pa $\mathrm{z}$ rezultati nekega vprašalnika, $\mathrm{s}$ katerim kandidat izkazuje (šolsko) znanje ali izraža svoja stališča; če drugega ne, bi morali psihologi pri presoji kandidatov upoštevati mnenje svetovalca za visokošolske poklice, kakršen je bil Lapajne. Sabini torej psihologija ni bila namenjena in omogočena. Prepričan pa sem, da bi bila tudi kot psihologinja uspešna.

Ker je možnost študija psihologije odpadla, se je Sabina hitro odločila za dvopredmetni študij pedagogike in sociologije. Odločila se je za andragoško usmeritev. Po končnem študiju, zlasti pri projektih, posebno raziskovalnih, ki jih je izpeljevala, se je pokazalo, da jo zlasti privlači sociološka razsežnost obravnavanih vprašanj, tako tudi izobraževanja odraslih. Prepričan sem, da je to zelo okrepilo njeno andragoško kompetentnost, ki se po mojem mnenju krepi toliko bolj, kolikor bolj se povezuje z drugimi strokami in razsežnostmi, med njimi seveda zlasti s sociologijo, pomembno pa gotovo tudi s psihologijo, pomembnim področjem, ki jo je tudi zanimalo. Tako je andragogika postala za Sabino kar ustrezna izbira.

Energija, živahnost, dinamičnost, odprtost, komunikativnost, dostopnost za srečevanje in stike so lastnosti, ki so odlikovale Sabino. Bila je živahen in zvedav otrok, ki si je s svojim vedenjem znala pridobiti naklonjenost tako staršev kot tudi drugih ljudi. Takoj se je bila pripravljena odzvati na pobude, ki so se pojavljale v njenem okolju, se kot otok vključevati v igro vrstnikov, se odzivati na družabne situacije in dejavnosti v svojem okolju, se vključevati v športne, kulturne, interesne in različne druge dejavnosti, ki so obstajale v njenem okolju in so jo vabile, da se jim pridruži in se vključi vanje. Rada se je pridružila petju, ko smo v družini, zlasti med vožnjo z avtomobilom, prepevali ljudske pesmi ali znane melodije; $\mathrm{z}$ veseljem se nam je pridružila, ko smo šli na pohode $\mathrm{v}$ naravo, bodisi v bližnje hribe bodisi v planine bodisi na morje ali pa v neznane domače in tuje kraje. Že zelo zgodaj je postala članica plavalnega kluba in je ves čas, ko je obiskovala osnovno šolo, trenirala plavanje; pri tem je bila zelo uspešna, saj je, ko je bila stara okoli 10 let, zasedla tretje mesto v Jugoslaviji v plavanju v prsnem slogu. Ko je postal trening zelo zahteven in je bilo treba trenirati trikrat na dan (zjutraj, pred šolo, takoj po šoli in zvečer), se je pametno odločila, da bo prenehala trenirati plavanje in bo začela trenirati skoke v vodo, ki so zahtevali manj časa. Obiskovala je likovne delavnice v Pionirskem domu in glasbeno šolo, kjer 
se je osem let učila klavir in prav toliko ali leto dlje kitaro. Zlasti kitara ji je prav prišla, da je zaigrala $\mathrm{v}$ družbi kot mladostnica ali kasneje ob različnih družabnih priložnostih. Občudovala je naravo in tuje kraje, kamor smo se napotili na potovanjih. Ko je postala profesorica na fakulteti, je bila med študentkami in študenti zelo priljubljena. Ves čas se je $\mathrm{v}$ razredu gibala med njimi in jih animirala, izogibala se je položaju predavateljice za katedrom. Študentke in študentje so jo radi prosili za mentorstvo pri diplomskih, magistrskih in doktorskih nalogah. Direktorica ljudske univerze iz Radovljice Mateja Rozman Amon je v svojem sožalnem sporočilu o njej napisala, da jo je zelo spoštovala in da je bila Sabina »vedno srčna, bojevita in prodorna strokovnjakinja na svojem področju, brez dlake na jeziku«, direktorica Zavoda za izobraževanje in kulturo Črnomelj Nada Žagar pa: »Globoko smo jo spoštovali in cenili kot strokovnjakinjo in žensko. Vedno se bomo spominjali prisrčnih in iskrivih srečanj ob različnih priložnostih, ko ni manjkalo toplih besed, spodbud, pohval in smeha.« Še pedagoginja mag. Marija Velikonja: »Sabino še vedno vidim kot sproščeno, prijazno, razgledano, delavno kolegico, ki je povezovala družbo ob sebi in pogosto premalo mislila nase.«

Kombinacija izbire poklicnih področij in osebnostnih značilnosti je tisto, kar je Sabini omogočilo, da je postala uspešna andragoginja. Morda bi lahko vse opisane značilnosti, ki so odlikovale Sabino, opredelili kot tisto optimalno osebnostno in vedenjsko strukturo, ki je potrebna za uspešno delovanje andragoga. Ponovimo: zanimanje za poklic s področja vzgoje in izobraževanja; pri tem je andragogika, delo z odraslimi, bolj ustrezna kot pedagogika in delo z otroki, zlasti v šolah; občutljivost za vprašanja strukture, razvoja in delovanja družbe ter skupnosti, vključno s politiko in kritičnostjo do nje; poznavanje človekovega duševnega ustroja in delovanja, vključno s hierarhijo vrednot in motivov; osebnostna in vedenjska dinamičnost, živahnost, energija, odprtost, komunikativnost, dostopnost za srečevanje in stike z ljudmi.

Sabinin primer sem opisal, ker se mi zdi živo udejanjenje lika uspešne andragoginje.

Zoran Jelenc 